Discussion Paper No. 07-065

\title{
Hydrogen in Passenger Transport: A Macroeconomic Analysis
}

Sabine Jokisch and Tim Mennel

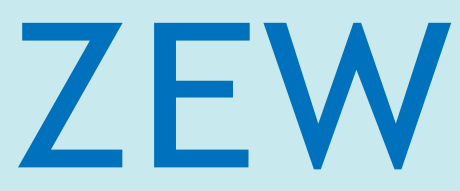

Zentrum für Europäische Wirtschaftsforschung $\mathrm{GmbH}$

Centre for European

Economic Research 


\title{
Discussion Paper No. 07-065 \\ Hydrogen in Passenger Transport: A Macroeconomic Analysis
}

\author{
Sabine Jokisch and Tim Mennel \\ Download this ZEW Discussion Paper from our ftp server: \\ ftp://ftp.zew.de/pub/zew-docs/dp/dp07065.pdf
}

Die Discussion Papers dienen einer möglichst schnellen Verbreitung von neueren Forschungsarbeiten des ZEW. Die Beiträge liegen in alleiniger Verantwortung der Autoren und stellen nicht notwendigerweise die Meinung des ZEW dar.

Discussion Papers are intended to make results of ZEW research promptly available to other economists in order to encourage discussion and suggestions for revisions. The authors are solely responsible for the contents which do not necessarily represent the opinion of the ZEW. 


\section{Non-technical Summary}

Rising oil prices and environmental problems arising from combustion of fossil fuels spur both public interest and research on alternative energy carriers. For the transport sector, hydrogen fuel cells are one of the technological options for the future. Building on modelling results of the EU project HyWays this working paper assesses the macroeconomic consequences of an introduction of hydrogen technology in the transport sector in 10 European countries (Finland, France, Germany, Greece, Italy, Netherlands, Norway, Poland, Spain, United Kingdom). Four scenarios are developed, varying in the projected penetration rate of hydrogen cars and the pace of technological progress.

The framework of the analysis is the dynamic computable general equilibrium (CGE) model PACE-T, developed at ZEW. A CGE model portrays the operation of many different economic agents (households, production sector etc.) simultaneously and numerically solves the path for all endogenous variables over a certain period. Such a model is suitable to determine the economy-wide repercussion effects of different policies. The analysis in this working paper focuses on the macroeconomic effects of introducing hydrogen cars in the transport sector which include changes in transport demand, real consumption, welfare, GDP and wage rates. The multi-sectoral PACE-T model features 12 regions - 10 HyWays Member States, the rest of the EU, and the rest of the world. Passenger cars in the model are split into six different car types. These are small, medium and large cars which are powered by either a conventional technology or hydrogen. Cars are implemented as durable consumption goods where conventional and hydrogen cars are assumed to be perfect substitutes. Consequently, the consumer's decision is based only on the price differences between hydrogen and conventional cars which depend on capital services of the automobile stock present in the respective economy, fuel consumption/expenses and expenditures for repair and maintenance. The hybrid PACE-T model integrates macroeconomic (so called 'top-down') and microeconomic ('bottom-up') data of the transport and fuel production sector. The top-down data consists of data on production and income generation as well as on revenues and expenditures of the different economic agents which are taken from the international GTAP database. It distinguishes energy inputs, non-energy inputs, labour and capital. The different hydrogen production, distribution and storage, and car technologies are specified through the generic cost structure, the import/export shares, the output in the business-as-usual case, and capacity constraints.

In order to implement passenger cars, which are powered by a conventional technology or hydrogen, demands further data on car and hydrogen production technologies. The bottom-up data is directly taken from the energy system model MARKAL. This data is mainly related to the capacity and production activity of various technologies and related parameters. Further information on the technical and economical characterisation of the hydrogen infrastructure technologies from the E3Database enters PACE-T via the MARKAL data. Given the output quantities and the cost structure of the different hydrogen technologies the aggregate production data of the industrial sectors is split down to accommodate a consistent bottom-up representation. The input structure of car and hydrogen production technologies is therefore adopted from the ISIS model. The analysis of the introduction of hydrogen in the transport sector is carried out relative to a baseline without hydrogen technologies. The scenario analysis then assumes hydrogen cars to become competitive via a learning curve approach.

The results show small improvements in the macroeconomic performance in almost all European countries from the introduction of hydrogen technology. The magnitude of economic effects depends, however, strongly on the assumptions on the penetration rate and technological progress. 


\title{
Hydrogen in Passenger Transport: A macroeconomic analysis
}

\author{
Sabine Jokisch \\ Ulm University \\ and \\ Tim Mennel \\ Centre for European Economic Research (ZEW), Mannheim
}

\begin{abstract}
Hydrogen is often seen as a promising future energy carrier given the major reliance of today's transport sector on finite fossil fuels. This working paper assesses the macroeconomic effects of introducing hydrogen as fuel in passenger transport within the framework of the computable general equilibrium (CGE) model PACE-T(H2). Our simulation results suggest small improvements in the macroeconomic performance in almost all European countries from the introduction of hydrogen. The magnitude of economic effects however depends on the assumed learning curve of hydrogen cars and on the future development of hydrogen infrastructure costs. The results presented in this paper build on data and projections developed in the EU funded 'HyWays' project.
\end{abstract}




\section{Introduction}

The sustainability of the transport system is one of the major challenges for the future in all developed countries. Rising oil prices in recent years have painfully shown the strong dependence of transport on fossil fuels. These trends in oil prices reflect supply shortfalls on international resource markets, political instabilities in supply regions and the expected longrun scarcity of fossil fuels. Undoubtedly, this will have major impact on Europe's future transport and energy system since about $50 \%$ of the energy consumption relies on imports (see EU Commission, 2007b). Furthermore, combustion of fossil fuels has major environmental impacts due to emissions of pollutants which may lead to long-term climate change. These concerns about climate change and energy supply have urged the discussion on possible alternatives to the reliance on finite fossil fuels. Hydrogen is often seen as a promising future energy carrier in the power and transport sector as well as a storage medium for renewable energy.

Today around 99\% of the final energy demand of European road transports depends on oil (see EU Commission, 2005). The EU Commission plans policies to replace $20 \%$ of traditional fuels in the road transport sector by alternative fuels (including biofuels, natural gas, and hydrogen) until 2020. Recently, the Commission has emphasized the necessity to introduce hydrogen fuel cells in the transport sector by 2030 (see EU Commission, 2007a). Given this high political priority, research on the use and broadening of hydrogen fuel cells in the transport sector has immensely increased over the last years.

The EU "HyWays" project ${ }^{1}$ is a research project that focuses on the prospects of hydrogen technologies. This project aims at developing a validated and well-accepted roadmap for the introduction of hydrogen in the energy system. In order to get a realistic quantification of the effects of a European hydrogen promotion policy, the project combines expertise from energy engineering, energy system modeling and economics. Therefore, data on a large array of hydrogen-related technologies are collected and processed in different kinds of models that allow investigating the technical, socio-economic and emission challenges and impacts of realistic hydrogen supply paths under consideration of technological and economical needs. This paper presents the results on macroeconomic consequences of introducing hydrogen as fuel in passenger transport under the assumptions of the HyWays project. The analysis is carried out within the framework of the computable general equilibrium (CGE) model PACE$\mathrm{T}(\mathrm{H} 2)$ which takes into account the economy-wide repercussion effects of the hydrogen promotion policy. A CGE model portrays the operation of many different economic agents (households, production sectors etc.) simultaneously and numerically solves the path for all endogenous variables over a certain period. The multi-sectoral PACE-T(H2) model features 12 regions - ten European countries, the rest of the EU, and the rest of the world. Passenger cars in the model are implemented as durable consumption goods and split into six different car types. These are small, medium and large cars which are powered by either a conventional technology or hydrogen. Conventional and hydrogen cars are assumed to be perfect substitutes. Consequently, the consumer's decision is based only on the price differentials between hydrogen and conventional cars which are based on capital services of the automobile stock present in the respective economy, fuel and expenditures for operation and maintenance. The analysis of the introduction of hydrogen in the transport sector is carried out relative to a baseline without hydrogen technologies. The scenario analysis then assumes hydrogen cars to become competitive via a learning curve approach.

Under the assumptions of HyWays the introduction of hydrogen in the transport sector leads to small improvements in the macroeconomic performance in almost all European countries. However, the economic effects depend heavily on the assumed learning curve of hydrogen

\footnotetext{
${ }^{1}$ For details of the HyWays project see the project webpage at http://www.hyways.de.
} 
cars and on the future development of hydrogen infrastructure costs. But also the path of fossil fuel prices affects the extent to which hydrogen cars become or do not become competitive in the future. Thus the cost differential between the lifetime costs of conventional and hydrogen cars determines primarily the consumers' budgets which finally drive the increase in consumption, welfare and GDP in the different scenarios.

This paper is organized as follows: The next section gives an overview of the CGE model applied for the macroeconomic analysis. Section 3 discusses the data sources and calibration of the CGE model. Section 4 provides the main scenario assumptions and presents the simulation results. Finally, section 5 concludes.

\section{Methodological Approach}

\subsection{General Model Description}

The multi-regional, inter-temporal CGE model PACE-T(H2) applied in this analysis builds on the PACE (Policy Assessment based on Computable Equilibrium) model, a large scale model of international energy use and global trade (Böhringer and Vogt, 2003). ${ }^{2}$ The original model was extended to include passenger transport services produced by cars with a conventional or a newly introduced hydrogen propulsion technology. Generally speaking, computable general equilibrium (CGE) models have become a standard tool for assessing economy-wide impacts of environmental and technological policies (for a survey of environmental applications see Conrad 1999, 2001). The CGE approach offers a comprehensive representation of pricedependent market interactions based on microeconomic theory. The simultaneous explanation of the origin and spending of agents' incomes allows addressing both economy-wide efficiency as well as distributional impacts of policy interference.

The current model version of PACE-T(H2) covers 12 regions. These are nine EU member countries (Finland, France, Germany, Greece, Italy, Netherlands, Poland, Spain, United Kingdom), Norway, the rest of the EU (plus Switzerland and Iceland), and the rest of the world. The model is set up as a perfect foresight model with optimal savings and investment decisions of the representative household who maximizes the present value of its lifetime utility given its intertemporal budget constraint. It is assumed that agents have an infinite lifetime, and forward-looking and rational expectations. Period length is chosen to be 10 years with the model horizon extending from 2000 to 2050.

Figure 1 gives an overview of the structure of the generic open-economy PACE model. A representative agent $R A r$ in each region $r$ is endowed with three primary factors: labour $L r$, capital $K_{r}$, and fossil-fuel resources $Q_{f f, r}$ (used for fossil fuel production). The representative agent maximises utility from consumption of a composite good $C_{r}$ (see Figure 2) which combines demands for energy and non-energy commodities at a constant-elasticity-ofsubstitution (CES) and transport services taking into account the intertemporal budget restriction, exhaustion of production in each period by consumption (domestic or export) and/or investment, and the equation of motion for the capital stock. The solution to the optimization problem of the household yields an optimal path for consumption over time. Since there is no explicit public sector in PACE-T(H2), all tax revenues are allocated to the representative household.

Production $Y_{\text {ir }}$ of commodities $i$ in region $r$ is captured by nested separable CES functions that describe the price-dependent use of capital, labour, energy and material in production. The sectoral disaggregation in PACE-T(H2) is comparable to other models with the focus on energy policy analysis. The full input-output decomposition of national accounts has been

\footnotetext{
${ }^{2}$ The general equilibrium structure of the model is based on Arrow and Debreu (1954).
} 
reaggregated into nine sectors (transport, energy intensive production, five energy sectors, the rest of production, and an aggregate investment good).

With respect to the intertemporal accumulation of productive capital, capital in each period is composed of the capital from the previous period (less depreciation) plus new investment, as commonly assumed. Depreciation and capital maturation rates have been adjusted to match the requirements of the 10-year periods in the model. The capital stock produces proportional capital services each year that enter the production functions. The proportionality factor has been calibrated according to the baseline interest rate. Investment into conventional productive capital is a Leontief-composite of output of all productive sectors with the share parameters determined through baseline investment.

The modelling of international trade is based on the Armington approach of product heterogeneity (Armington, 1969), so that domestic and foreign goods of the same variety are distinguished by their origin. All goods used on the domestic market in intermediate and final demand correspond to a CES composite Air that combines the domestically produced variety $Y_{i r}$ and imports $M_{i r}$ of the same variety from other regions. Domestic production $Y_{\text {ir }}$ either enters the formation of the Armington good Air or is exported ( $\left.X_{i r}\right)$ to other regions. Trade with other regions is represented by a set of horizontal export demand and import supply functions at exogenous world import and export prices with these relative prices determining the demand for imports and the shares of imports from the different countries. A balance of payment constraint, which is warranted through flexible exchange rates, incorporates the benchmark trade deficit or surplus. In equilibrium, there is a period-by-period balance between exports from each region and global demand for those goods. The only exception to the Armington approach is the international crude oil market, which has been homogenised so that every country either imports or exports crude oil, and the world market for passenger cars. The latter pools car exports from all countries and serves each country's demand for imports without distinguishing between the car's producing country.

The model is formulated as a system of nonlinear inequalities using GAMS/MPSGE (Rutherford 1999) and solved using PATH (Dirkse and Ferris, 1995). The inequalities correspond to the three classes of conditions associated with a general equilibrium: (i) exhaustion of product (zero-profit) conditions for constant returns to scale producers, (ii) market clearance for all goods and factors, and (iii) income balance for the representative consumers in each region. The fundamental unknowns of the system are activity levels (production indices), non-negative prices, and consumer incomes. In equilibrium, each of these variables is linked to one inequality condition: an activity level to an exhaustion of product constraint, a commodity price to a market clearance condition, and a consumer income variable to an income definition equation. An equilibrium allocation determines production, prices and incomes. All output and factor prices are fully flexible and markets are perfectly competitive.

\subsection{Passenger Transport and Hydrogen Application}

An essential extension of the PACE-T model is the modeling of passenger cars as durable consumption goods (see Boeters et al., 2004). The representative household does not consume cars as such but transport services ${ }^{3}$. As shown in Figure 2, these services are produced with various inputs which are composed of capital services of the automobile stock in the respective economy, fuel and other expenditures (for operation and maintenance, O\&M). In order to preserve macroeconomic consistency, the consumption of passenger car transportation services has been subtracted from the aggregate consumption value of the respective national accounts.

\footnotetext{
${ }^{3}$ Transport services describe the household's demand for vehicle kilometres. The transport sector in commodity production captures all other transport services excluding passenger transport.
} 
The automobile capital stock is treated very similar to the stock of productive capital, i.e. the stock of automobile capital is composed of the stock in the previous period less depreciation plus new investment. This captures the fact that adjustment of the average automobile characteristics is not instantaneous. Cars from earlier vintages contribute to a certain extent to the production of current transport services. The durability of cars is assumed to be 12 years. Depreciation and capital maturation rates comply with the requirements of one model period. Technology coefficients are time varying depending on the development of fuel and other costs. There are three different automobile types: small, medium and large cars. Since the model does not account for a separate automobile industry sector, the production of new cars is assigned to the macro-good production sector, i.e. the value of automobile production is subtracted from the aggregated value of macro-good production. This implies that automobile production has the same input structure as the macro-good sector.

Hydrogen enters PACE-T(H2) as fuel for passenger cars. Thus we introduce a separate automobile capital stock for hydrogen cars. Consumers in the model choose between transportation services produced by either the conventional technology or by hydrogen powered passenger cars.

The major difficulty in the calibration of the demand function is the lack of detailed empirical data on hydrogen car demand. Both car technologies (conventional and hydrogen) are therefore treated as perfect substitutes. The baseline simulation in PACE-T(H2) assumes the hydrogen technology to be inactive. In the scenario analysis the share of hydrogen cars in overall new passenger cars (penetration rates) is set exogenously ${ }^{4}$. Since consumers always choose the cheapest alternative, the more expensive technology would simply be withdrawn from the market. In order to prevent such a development, both technologies have to be equally expensive. This is reached by either taxing or subsidizing the hydrogen technology. The respective amounts are lump-sum transferred to the consumer.

The assumption that conventional and hydrogen cars are perfect substitutes seems to be relatively unrealistic given the fact that there are further factors affecting car demand like e.g. noise or driving properties. However, due to the lack of detailed empirical data on hydrogen car demand there is no possibility to calibrate a more flexible demand function.

The relative advantage or disadvantage, and thus the economic impact, of introducing the new hydrogen technology is determined by the relative cost difference between conventional and hydrogen cars. Total automobile costs are calculated as the sum of purchase and utilisation costs for both hydrogen and conventional cars over their lifetime where utilisation costs are further decomposed into fuel costs and other costs. The value of the cost difference between conventional and hydrogen cars highly depends on whether taxes for conventional fuel are taken into account or not. The comparison of net costs allows determining when hydrogen cars become competitive. This is essential for the welfare implications of introducing hydrogen cars. Gross car costs, calculated from the car and fuel prices including fuel taxes (for conventional fuels), are important for the consumer's car purchasing decision. The use of hydrogen as fuel input in passenger transport demands a hydrogen production technology. The model therefore features a separate sector for hydrogen production which is characterised by fixed input shares for the various inputs. These inputs differ between the considered countries due to the country-specific mix of hydrogen production technologies with different fuel or electricity inputs reached from energy system models. The aggregate hydrogen production technology in PACE-T(H2) is characterised by the average costs of hydrogen production calculated as the sum of costs for investment, fuel inputs and O\&M for the various production and distribution technologies.

Finally, all scenarios analysed with PACE-T(H2) assume the international import-export structures of hydrogen and conventional cars to be the same (structural identity). This means

\footnotetext{
${ }^{4}$ These penetration rates are taken from the results of the MARKAL model, compare Section 4.
} 
that if a country is producing and exporting conventional cars at present, the assumption is made that this country will also produce and export hydrogen cars in the future.

\section{Data and Calibration}

As explained in the previous section the approach of PACE-T(H2) combines a macroeconomic (top-down) view of the economy as a whole and a microeconomic (bottomup) view of the energy and transport sector. Correspondingly, for its calibration both topdown and bottom-up data are used. The top-down data stem from the GTAP database. The bottom-up data on car and hydrogen technologies are taken from the energy-system model MARKAL, and data on the input structure of these technologies are adopted from the inputoutput model ISIS.

\subsection{Data sources}

The most important data source is the dataset of the Global Trade Analysis Project (GTAP), an international research program at the Center for Global Trade Analysis at Purdue University. It has established a global economic dataset for quantitative analysis of research topics in international economics. This dataset provides a basis for the calibration of many CGE models (see Bhattacharyya, 1996), among them PACE. Social accounting matrices $\left(\mathrm{SAMs}^{5}\right)$ are used to calibrate the top-down structure in these models. In this analysis, we apply the GTAP5 version of the database (GTAP, 2002), which distinguishes between 66 regions, 57 sectors, and 5 factors of production. ${ }^{6}$ As already explained above, this regional and sectoral decomposition has been reaggregated into 12 regions and nine production sectors within PACE-T(H2).

The MARKAL model family (acronym for MARKet ALlocation) consists of different versions of a dynamic bottom-up model of the energy system, developed in the framework of the Energy Technology Systems Analysis Programme (ETSAP) of the International Energy Agency (IEA). ${ }^{7}$ In the HyWays project, the Energy Research Centre of the Netherlands (ECN) calculated the costs of various car, energy and hydrogen technologies with its version of MARKAL. ${ }^{8}$ The model spans various sectors of the energy system and more than a thousand technologies. Basically, it is a demand driven model that minimises energy costs over a given time period. The cost specifications of technologies as well as labour and energy carriers determine the outcome of the technology mix. In particular, different technologies of a hydrogen economy, i.e. production, transport and non-transport consumption, are incorporated in the model. The technical and economical information is taken from the E3Database (see Jeeninga et al. (2007)). The research focus on hydrogen technologies in the transport sector demands an extension of the cost structure for private transport in MARKAL, subdividing transport demand into three classes: city, regional and long-distance transport. Three classes of cars were introduced to serve the specific demand: small, medium and large cars, each specified with a conventional and hydrogen technology. For the project, ECN developed a projection of transport demand and implemented it in MARKAL that is based on the assumption of converging car ownership in all member states by 2030 to the level of Germany (for a detailed description see Jeeninga et al., 2007) Future developments of hydrogen technologies (the industry's learning curve) and the market penetration of hydrogen

\footnotetext{
${ }^{5}$ A Social Accounting Matrix (SAM) represents flows of all economic transactions that take place within an economy (regional or national). It is a statistical representation of the economic and social structure of a country.

${ }^{6}$ For a detailed description of the GTAP5 database and model see Rutherford (1998).

${ }^{7}$ See Seebregts et al. (2001) for a description of MARKAL.

${ }^{8}$ At ECN, a first version of MARKAL was used to describe the Dutch energy system, later it was extended to the Western European energy system (see Martinus et al., 2005, and Smekens, 2005).
} 
cars are both interdependent and more difficult to project than demand. Consequently, the modelling groups in HyWays agreed on four scenarios specifying both cost reductions in production and penetration rates that are described below.

The input structure of the various hydrogen technologies in PACE-T(H2) are taken from the ISIS model (acronym for Integrated Sustainability Assessment System) developed by the Fraunhofer Institute for System and Innovation Research (ISI), Karlsruhe. ${ }^{9}$ It is based on an input-output model for Europe, dividing each of the member states covered into 59 manufacturing sectors and 6 sectors of final demand. This allows for an analysis of supplies of goods and services between manufacturing sectors (intermediate demand) and supplies from these to the final demand sectors. The model is calibrated on data from European Statistical Office (Eurostat) for the year 2000.

\subsection{Calibration}

In the following we briefly describe how the data from the various sources were used to calibrate the PACE-T(H2) model. As stated above, the GTAP database offers consistent accounts of national production and consumption, bilateral trade and energy flows. The benchmark data for quantities and prices together with exogenous elasticities determine the free parameters of the functional forms. Given these benchmark data the model is calibrated to a steady-state growth path assuming an interest rate of $4 \%$ and an average annual growth rate of 2.3\% and to the exogenous oil price path given in EU Commission (2006).

The calibration of the conventional car production technology and of the hydrogen economy, i.e. the bottom-up structure of hydrogen fuel production, hydrogen car production and hydrogen infrastructure, is based on the output of MARKAL.

Lifetime costs of conventional and hydrogen cars are calculated as the sum of purchase and (time-discounted) utilisation costs, where utilisation costs are further decomposed into fuel and other costs. As mentioned above, the subdivision of car classes (small, medium and large) mimics the one in MARKAL. Purchase costs are calculated as weighted average of investment costs. To obtain annual fuel costs, average fuel consumption per car is multiplied with the fuel price. As for conventional fuel, taxation greatly influences its price.

Consequently, we distinguish between net and gross costs of conventional cars, assuming that hydrogen cars are left untaxed. Tax data on conventional fuels are taken from DIW (2002) and MWV (2005).

Hydrogen production costs are heterogeneous across countries because each country relies on different technologies for hydrogen production. Costs also differ across time: In the initial phase of hydrogen transport, hydrogen fuel produced as a by-product in the industrial process covers a significant part of demand. As demand increases, steam methane reforming becomes the major production technology. ${ }^{10}$ Average costs of hydrogen production are calculated by summing costs of investment, fuel inputs and O\&M costs. Investment costs accrue both for the set-up of new generation plants and distribution facilities. The costs given in MARKAL are annualised with the yearly depreciation rate (assuming linear depreciation). Average fuel costs in each country are calculated as a weighted average over all production technologies and their respective fuel inputs. O\&M costs are aggregated over all technologies and divided by total hydrogen production. Given the output quantities and the cost structure of the different hydrogen technologies sectoral production is split up to accommodate a consistent bottom-up representation in the top-down model according to the input structure of hydrogen production technologies from the ISIS model.

\section{Scenarios and Results}

\footnotetext{
${ }^{9}$ For a description of the ISIS model used in the HyWays project see Wietschel and Seydel (2007).

${ }^{10}$ For details on the mix of hydrogen production technologies in the HyWays project see Martinus et al. (2005).
} 
In the following we describe in more detail the model scenarios and the results of the analysis with PACE-T(H2). Both the learning curve of the hydrogen technology and the penetration rate for hydrogen cars are crucial as well as difficult parts of the calibration. A learning curve is essentially a prediction about future technological development, which is uncertain in nature and cannot be sensibly made by economists. It then determines the production cost. Given these, penetration rates for a certain product depend on consumer demand on the resulting price and quality of the product, and as such they are a topic for economic study. However, given the lack of a market for hydrogen cars today there are no empirical studies for consumer demand for hydrogen technologies. Therefore, the HyWays consortium formed a scenario task force of experts from industry and research that agreed to study four scenarios combining different degrees of technological progress with varied penetration rates of the hydrogen technology. ${ }^{11}$ In the following, we concentrate on two scenarios: The first scenario, labelled $\mathrm{H} 2 \mathrm{H}$, assumes a high rate of cost decrease for the hydrogen technology and a high hydrogen penetration rate. The second scenario, labelled L2L is more pessimistic. It implements a less steep learning curve and low hydrogen penetration rates. ${ }^{12}$ The details of the scenarios alongside the results of the model runs with PACE-T(H2) are shown in the next sections. As already stated above, the benchmark for economic comparison (referred to as baseline) is business-as-usual, i.e. economies developing without hydrogen technology.

\subsection{Hydrogen penetration rates}

Penetration rates are defined as the share of hydrogen cars per size category, per period and per country. As explained in the previous section, penetration rates for each size category are calculated in MARKAL and implemented in PACE-T(H2) exogenously. Figure 3 shows the penetration rates for small, medium sized and large new hydrogen carsin the $\mathrm{H} 2 \mathrm{H}$ scenario respectively for all countries. There is a steep increase in the penetration rate after 2010 with considerable differences across countries: In the early phase of hydrogen technology, in 2020, the penetration rates vary between 1 and $15 \%$ across countries for all car sizes. In most countries hydrogen cars become dominant in the large size category after 2030, in the medium size category after 2040. In 2050 penetration rates for these categories vary between 80 and $100 \%$. For small cars, the increase is generally more moderate. In 2050, penetration rates for small cars vary between $51 \%$ for Norway and $88 \%$ for Poland.

Figure 4 shows the penetration rates for all size classes in the L2L scenario. By definition of the scenario, these are lower than in the $\mathrm{H} 2 \mathrm{H}$ scenario. In this scenario the shares of hydrogen cars do not rise significantly before 2020. Only large hydrogen cars reach market dominance in 2050 for most countries, albeit with a large variation: While for Germany, Italy, Norway and the Netherlands they crowd out conventional cars entirely, in Finland and Poland the share is below 60\%, in Norway it is $19 \%$. In the case of middle sized cars, Germany and Poland show a steep increase of penetration rates, culminating in a market share for hydrogen cars of 99\% and 92\% in 2050 respectively. For the other countries the share of hydrogen cars varies between 54\% for Spain and Italy and 23\% for France. For small cars, the penetration rate is considerably lower than in the $\mathrm{H} 2 \mathrm{H}$ scenario and also lower than in the two other car

\footnotetext{
${ }^{11}$ While the overall penetration rates of hydrogen cars were assumptions made in the task force, the relative penetration rates of different car sizes stem from the analysis in MARKAL. For more details on the scenario assumptions see HyWays (2007).

12 Jokisch and Mennel (2007) also present and discuss the results of the H2M scenario, which combines a high cost decrease with medium hydrogen penetration, as a sensitivity check. This scenario essentially confirms the conclusions drawn here.
} 
size categories. In 2030, their share is below 10\% in all countries, in 2050 they account for roughly a quarter of small cars: shares vary between $30 \%$ in the UK and $23 \%$ in Italy, Norway and France between $60 \%$ and $50 \%$ in the majority of countries.

Average penetration rates of hydrogen cars for 2050 show the difference between the $\mathrm{H} 2 \mathrm{H}$ and L2L scenarios most clearly: In the H2H scenario, the market share of hydrogen cars will reach almost $90 \%$ in Germany and $85 \%$ in Italy while the majority of countries (Finland, Greece, Netherlands, Spain, Poland, Norway, UK) has a penetration rate of around $80 \%$. In contrast, the bulk of countries in the L2L scenario (Finland, Greece, Netherlands, Spain, Poland, Norway, UK) has a penetration rate between 60 and 50\%, with two outliers: Germany with $75 \%$ and France with $23 \%$. Summarizing we can say that, while there are differences of 20 to $25 \%$ in penetration rates in the scenarios, the prediction in both is that hydrogen technology will dominate private transport by 2050 .

\subsection{Cost comparison}

In this subsection we have a closer look at the costs of passenger transport since these drive the effects on macroeconomic development analysed with PACE-T(H2). Remember from section 2 that total transport costs are calculated as an aggregate of hydrogen and conventional transport costs, weighted according to the penetration rates of hydrogen cars. In their disaggregated form, costs of transport consist of car purchase, fuel and operation and maintenance costs for conventional and hydrogen technology respectively. As explained in section 3, cost data stem from the MARKAL model. In the $\mathrm{H} 2 \mathrm{H}$ scenario a fast rate of cost reduction is assumed, in the $\mathrm{L} 2 \mathrm{~L}$ scenario a moderate one. We have to distinguish between gross and net costs of transport: From the macroeconomic viewpoint car lifetime costs net of taxes are essential for the competitiveness of hydrogen and conventional cars, whereas car lifetime costs including taxes are essential for consumer's purchase decisions. To present the cost development in graphical detail, we have chosen three countries (Poland, Italy and Finland) and one car-size category (large cars). ${ }^{13}$ As will become obvious in the sequel, the chosen countries represent the top winner from the introduction of hydrogen technology, an average winner and a non-gainer, respectively. The case of the other member states and car categories is discussed in the text.

Figure 5 shows the development of total costs for large hydrogen cars (including purchase, fuel and operation and maintenance costs) as well as for large conventional cars gross and net of fuel taxes in the H2H scenario, Figure 6 the costs in the L2L scenario. Graphs start in 2010 with market maturity of the hydrogen technology. In the $\mathrm{H} 2 \mathrm{H}$ scenario, gross costs of conventional cars in each of the three countries (and indeed, in all countries studied in the project) exceed those of hydrogen cars, whereas the cost curves of hydrogen cars and conventional cars net of tax cross at least once. In all countries costs of hydrogen cars decline such that by 2020 they are competitive with conventional cars. A decomposition of cost factors shows that this effect is driven by the decline in car production costs, reflecting the predicted learning curve. After 2020, hydrogen costs slightly increase in Italy and Finland, which is representative of the development in most countries. In Poland, hydrogen costs fall until 2030 and remain stable thereafter. The driving force behind these developments is the cost increase for hydrogen fuel that becomes more expensive the more it is produced. Also, the price for hydrogen fuel is of course influenced by the price development of primary energy carriers. The comparison to the cost development of conventional cars, that is mainly influenced by an increase in oil prices, shows a heterogeneous picture across countries: After 2030, costs of hydrogen cars exceed those of conventional cars in Finland, France and Norway, whereas in Spain, Germany, the Netherlands and Poland they remain lower (in Italy

\footnotetext{
${ }^{13}$ The full set of cost developments is shown in Jokisch and Mennel (2007).
} 
they rise above those of conventional cars only after 2040). The cost difference varies between 0 and 10\%. In Poland, the cost reduction of hydrogen cars is most significant, reflecting particularly cheap hydrogen fuel costs: in 2050 hydrogen cars are more than $20 \%$ cheaper than conventional cars with respect to their lifetime costs. The comparison of lifetime costs of hydrogen and conventional cars in the small and medium size category gives roughly the same picture as in the case of large cars, only that differences are less pronounced. In the L2L scenario the costs of conventional cars are the same as in the H2H scenario. As before, gross costs for large conventional cars are well above those of large hydrogen cars. In contrast, the latter fall below net costs of the former only in 2030. In Italy the order is reversed in 2040, as it is in roughly half the member states. Finland and Poland represent the other half, where large hydrogen cars remain cheaper than conventional ones after 2030. Again, increasing fuel and decreasing production costs exert a countervailing influence on total costs.

In the case of medium sized cars there is a significant difference between the $\mathrm{H} 2 \mathrm{H}$ and $\mathrm{L} 2 \mathrm{~L}$ scenario: Whereas hydrogen cars become cost competitive after 2020 in the former, they do not become competitive in the latter before 2040 in any country; in France, Germany, Italy, Norway and the UK they do not become competitive at all. This mainly reflects the slower decrease of producer costs in the L2L scenario. The case of small cars is in-between: After 2030, costs of hydrogen and conventional cars are almost identical in most countries.

\subsection{Economic development}

Now we turn to the macroeconomic effects of introducing hydrogen cars in passenger transport. Our focus here is on the development of GDP, transport demand, real consumption, welfare and the wage rate. As already explained before, the simulation analysis with PACE$\mathrm{T}(\mathrm{H} 2)$ builds on the calibration and the scenario assumptions of the $\mathrm{H} 2 \mathrm{H}$ and L2L scenario presented above.

The development of GDP as calculated in our simulation is shown in Figures 7 and 8 for the $\mathrm{H} 2 \mathrm{H}$ and L2L scenario, respectively ${ }^{14}$. Both figures display relative changes of the variables with respect to the baseline (scenario without hydrogen technology) for all member states. Two tendencies emerge from the results: First, changes in production are small (with the exception of Poland). Second, there is considerable heterogeneity in the results. In the $\mathrm{H} 2 \mathrm{H}$ scenario modest increases in GDP after 2020 are observed for all countries except Finland, which experiences a - negligible - loss of $0.03 \%$ of GDP by 2050. In contrast, Poland gains $2.2 \%$ in GDP by 2050, thus clearly outperforming all other member states. Spain achieves an increase in GDP of $0.6 \%$ by 2050 , the increase in the other member states varies between $0.05 \%$ and $0.26 \%$. In the L2L scenario the picture is different: If at all, the rise of GDP starts only in 2040 and is considerably less pronounced than in the H2H scenario. Again, Poland shows a remarkable gain of $1.1 \%$ in GDP by 2050. Spain and Finland experience increases in their GDP, too. In the Netherlands, Greece, France and Germany, GDP remains roughly the same as in the baseline. In Norway, Italy and the UK it drops by $0.1 \%$.

The heterogeneous developments of production across countries reflect both the heterogeneous cost developments and penetration rates of hydrogen cars. A cost decrease of hydrogen below the cost of conventional cars explains the (albeit modest) rise of GDP in most countries, with the effect being most noticeable where the share of hydrogen cars is high (compare the previous subsections). Countries with high hydrogen production costs, such as Finland in the $\mathrm{H} 2 \mathrm{H}$ scenario, show the reversed effect. Consequently, gains in GDP are higher in the $\mathrm{H} 2 \mathrm{H}$ than in the L2L scenario, where the market maturity of hydrogen technology

\footnotetext{
${ }^{14}$ One word of caution is warranted concerning these results: Costs of innovation are not included in the analysis. We assume that they are small in comparison to the overall economic development. The figures show effects of cost reductions in production taken technological progress as given..
} 
unfolds later and penetration rates remain low. As can be seen from the previous subsection, the large gain for Poland is produced by particularly low production costs of Polish hydrogen fuel. Table 1 reports the relative deviation of transport demand in 2050 from the baseline for the two scenarios.In the $\mathrm{H} 2 \mathrm{H}$ scenario, Poland experiences a $1.3 \%$ increase in transport demand by 2050. Spain displays the largest increase next to Poland, and Finland the lowest ( $0.5 \%$ and $0.1 \%$ respectively). In the L2L scenario Poland oversees an equilibrium gain in transport demand of $0.5 \%$ by 2050, Norway, Spain and the Netherlands $0.2 \%$ while Germany, Italy and the United Kingdom experience temporary losses which do not, however, exceed $0.1 \%$. The increase in transport demand in most countries is essentially a wealth effect due to lower transport costs with cheap hydrogen cars. The wealth effect is also evident in the development of real consumption ${ }^{15}$ in the $\mathrm{H} 2 \mathrm{H}$ and L2L scenario (see Table 1). The figures indicate that the increase in real consumption and in transport demand is highly correlated. Again, Poland is the big winner of an introduction of hydrogen technology with an increase of real consumption by $1.2 \%$ by 2050 ( $0.5 \%$ in the L2L scenario). The other countries also gain or lose as much in consumption in general as in transport in particular: There is a rise of consumption up to $0.4 \%$ in the H2H scenario for Spain and $0.2 \%$ for Norway in the L2L scenario by 2050 , with any losses generally being negligible in the former and small (no more than $0.1 \%$ ) in the latter. Thus consumers use the higher budget engendered by cheap hydrogen transport for higher general consumption and more transport in almost equal shares.

Furthermore Table 2 shows the change of real wage rates in 2050 vis-à-vis the baseline in both scenarios. The picture differs from the economic variables considered above insofar as all changes are much more moderate - below $0.5 \%$ for all countries in both scenarios. In the $\mathrm{H} 2 \mathrm{H}$ scenario four member states experience a rise of wages - of (less than) $0.1 \%$ in 2050 -, six others a fall (the biggest fall occurs in Poland with $0.4 \%$ ). In the L2L scenario, the number of gainers and losers remains the same, with the effects dampened in comparison to the $\mathrm{H} 2 \mathrm{H}$ scenario. Poland, where again the effect is largest, experiences a wage loss of $0.3 \%$. A detailed explanation of the difference in the development of wages in comparison to consumption would have to analyse the production process across all sectors. Short of attempting that we may conclude, though, that consumption gains reflect higher capital income, reflecting the high capital intensity of the hydrogen technology.

Social welfare is measured as Hicks equivalent variation (HEV) defined as the weighted average of real consumption over all periods. Table 2 reports the percentage changes in welfare of the ten member states for both the $\mathrm{H} 2 \mathrm{H}$ and L2L scenario. As the figures indicate, consumers in all countries gain by the introduction of hydrogen transport in the former scenario while they lose in two of ten countries in the latter. All changes are moderate, except for Poland which achieves a welfare gain of $1.2 \%$ in the $\mathrm{H} 2 \mathrm{H}$ scenario $(0.5 \%$ in the $\mathrm{L} 2 \mathrm{~L}$ scenario). Spain gains $0.4 \%$ in consumption, Finland little more less than $0.1 \%$ in the $\mathrm{H} 2 \mathrm{H}$ scenario. In the L2L scenario, welfare changes vary between $+0.2 \%$ for Norway and $-0.1 \%$ for Italy and the UK.

\section{Conclusion}

What do we learn from the simulation analysis about the likely economic impact of an introduction of hydrogen as a fuel in passenger transport? According to our results, the introduction of hydrogen cars impacts the future macroeconomic development. Although these results differ in their extent across scenarios (with either high or low predicted penetration rates and either a steep or flat cost decrease of hydrogen cars), we can summarize the following qualitative tendencies: GDP will increase with respect to a baseline without hydrogen technology in all considered countries in the long run, albeit with considerable

\footnotetext{
${ }^{15}$ Real consumption is an aggregate of all consumption goods including transport.
} 
differences across countries. The resulting welfare gain is driven by the predicted fall of hydrogen transport cost below conventional transport cost. Consequently, both transport demand and real consumption increase in all countries. Having said that, the changes of transport demand, real consumption, welfare, GDP and the wage rate in the scenarios compared to the baseline are rather small and must be cautiously interpreted. General equilibrium effects tend to work against possibly large partial or first-round effects in increased hydrogen use. The differences in economic outcomes between countries can be traced back to the net of tax cost differences between hydrogen and conventional car lifetime costs. These cost differences in turn are partly explained by the hydrogen production technologies chosen in the considered countries.

The size of the effects depends on the scenario assumptions. First, it is important how fast the costs for hydrogen production decrease over time. The difference between lifetime costs for conventional and hydrogen cars shows the cost savings from implementing a new technology - or their additional costs. Cost savings are highest where the cost decline for hydrogen cars will be highest in the future. Whereas in the long run no country loses by the introduction of hydrogen cars, some may experience losses on the transition. Second, the penetration rates determine how much of the cost savings potential will become active in the countries. Third, we have assumed that costs of innovation are small in comparison to the overall economic development. Altogether these factors heavily determine the consequences on the consumer's budget which again affects transport demand, real consumption and thus GDP. Welfare is then determined by the deviation of real consumption to the baseline.

Of course, one must not forget that the extent to which the introduction of hydrogen cars affects the macroeconomic development also depends on the lifetime costs for conventional cars. This not only concerns car production costs but more importantly the development of future fuel prices. The difference between lifetime costs of conventional and hydrogen cars determines the level of the cost savings potential from the introduction of a new technology which finally impacts the macroeconomic variables.

Finally, as already discussed, the results in PACE-T(H2) are also affected by the assumption to treat hydrogen and conventional cars as perfect substitutes. This causes households to simply choose the cheapest technology. Of course, this assumption is critical given that car demand depends on further factors like e.g. noises or driving properties of the car. Relaxing this assumption might probably impact the simulation results. However, it is simply impossible to calibrate a more flexible demand function since there are no empirical data on hydrogen car demand available.

Bearing in mind the caveats concerning uncertainty both about technological progress and its cost and consumer demand, we can say that our results suggest that the introduction of hydrogen transport is likely to be beneficial for countries analyzed in this article in economic terms. The fall in transport cost, predicted by engineers, by an introduction of hydrogen cars will benefit consumers who are likely to increase their demand for transport and to consume more in general. Whether hydrogen technology is superior to alternative new propulsion technologies - such as biofuels - remains a research topic of its own. For economists, research into consumer preferences for different means of transport will be necessary to shed light on the future of individual mobility. 


\section{References}

Armington, P. (1969), A Theory of Demand for Products Distinguished by Place of Production, IMF Staff Papers 16, 159-178.

Arrow, K.J. and G. Debreu (1954), Existence of an Equilibrium for a Competitive Economy, Econometrica 22, 265-290.

Bhattacharyya, S.C. (1996), Applied General Equilibrium Models for Energy Studies; a Survey, Energy Economics 18, 145-164.

Boeters, S., C. Böhringer and A. Löschel (2004), How to Regulate CO2-Emissions of Passenger Cars in Europe? - An Applied General Equilibrium Analysis, Discussion Paper, ZEW Mannheim.

Böhringer C. and C. Vogt (2003), Economic and Environmental Impacts of the Kyoto Protocol, Canadian Journal of Economics 36, 475-494.

Conrad, K. (1999), Computable General Equilibrium Models for Environmental Economics and Policy Analysis. In: van den Bergh, J C J M (ed) Handbook of Environmental and Resource Economics. Edward Elgar, Cheltenham, 1061-1087.

Conrad, K. (2001), Computable General Equilibrium Models in Environmental and Resource Economics, in: T. Tietenberg and H. Folmer (eds.): The International Yearbook of Environmental and Resource Economics 2002/2003, 66-114.

Dirkse, S.P. and M.C. Ferris (1995), The PATH Solver: A Non-Monotone Stabilization Scheme for Mixed Complementarity Problems, Optimization Methods and Software 5, 123156.

DIW (2002), Europäischer Vergleich der besonderen Steuer- und Abgabensysteme für den Erwerb, das Inverkehrbringen und die Nutzung von Kraftfahrzeugen, Endbericht, Berlin, [in German].

EU Commisison (2005), The Annual Energy and Transport Review for 2004, Brussels.

EU Commission (2006), World Energy Technology Outlook - 2050. WETO-H2, Brussels.

EU Commisison (2007a), An Energy Policy for Europe. Communication from the

Commission to the European Council and the European Parliament, COMM(2007) 1 final, Brussels.

EU Commisison (2007b), EU Energy and Transport in Figures, Statistical Pocketbook 2006, Brussels.

GTAP (Global Trade, Assistance, and Production) (2002), The GTAP5 Data Base, Center for Global Trade Analysis, Purdue University, West Lafayette.

HyWays (2007), HyWays - A European Roadmap, see http://www.hyways.de, forthcoming.

Jeeninga, H. and G.H. Martinus (2007), Energy System Modelling of a Hydrogen Economy, Background report HyWays Phase II, ECN, see http://www.hyways.de, forthcoming

Jokisch, S. and T. Mennel (2007), Report of Macroeconomic Analysis, Deliverable 3.18, HyWays, see http://www.hyways.de, forthcoming.

MWV (Mineralölwirtschaftsverband) (2005), Mineralöl-Zahlen 2004, Hamburg, [in German]

Martinus, G.H., K.E.L. Smekens, H. Rösler (2005), Energy system modelling of a hydrogen economy - MARKAL model extensions and results, Report for the HyWays Project, ECN.

Rutherford, T. F. (1998), GTAPinGAMS: The Dataset and Static Model, Working Paper, University of Colorado. 
Rutherford, T.F. (1999), Applied General Equilibrium Modelling with MPSGE as a GAMS Subsystem: An Overview of the Modelling Framework and Syntax, Computational Economics 14, 1-46.

Seebregts, A.J., G.A. Goldstein and K. Smekens (2001), Energy/Environmental Modeling with the MARKAL Family of Models. In Proceeding of the OR2001 Conference, University of Duisburg- Essen, Duisburg, Germany.

Smekens, K. E. L. (2005), Technology R\&D and CO2 policy scenarios. The MARKAL model work for SAPIENTIA, ECN Working Paper ECN-C--05-059.

Wietschel, M. and P. Seydel (2007), Economic impacts of hydrogen as an energy carrier in European countries, International Journal of Hydrogen Energy, forthcoming. 


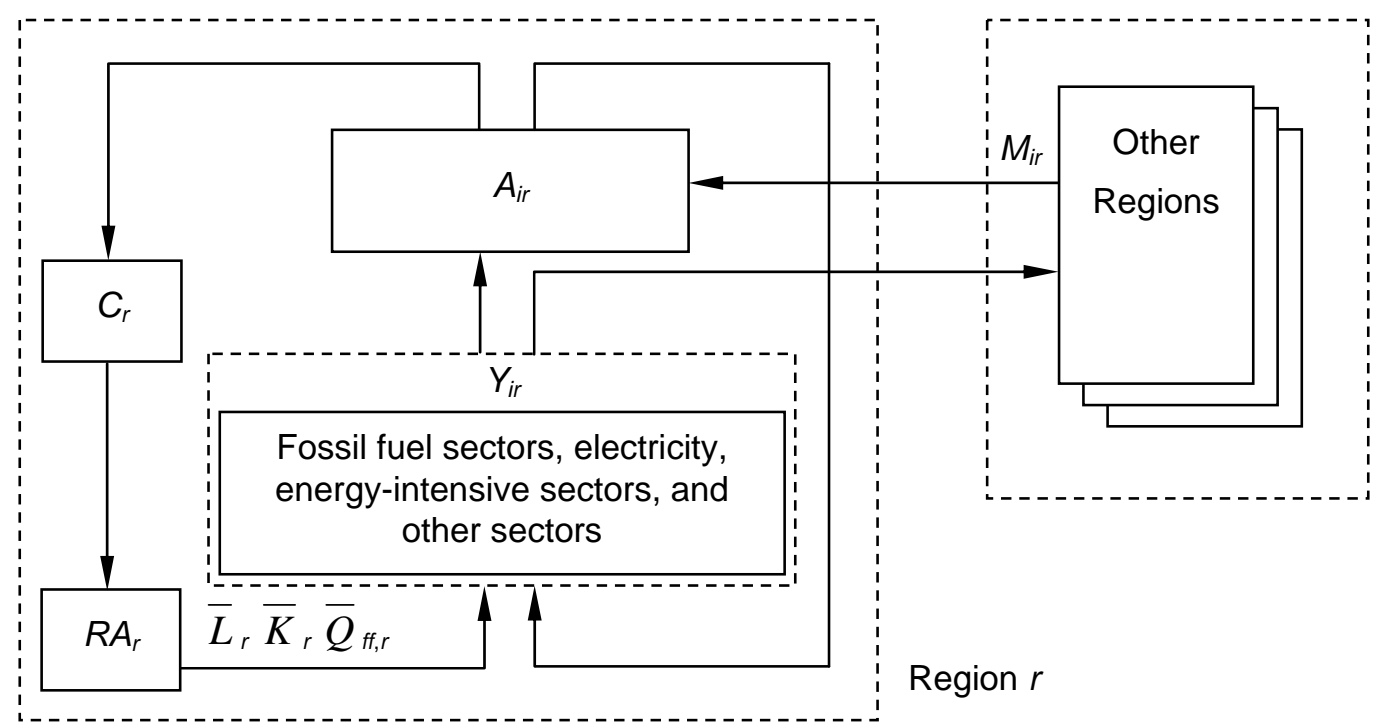

Figure 1: Overview of the Model Structure

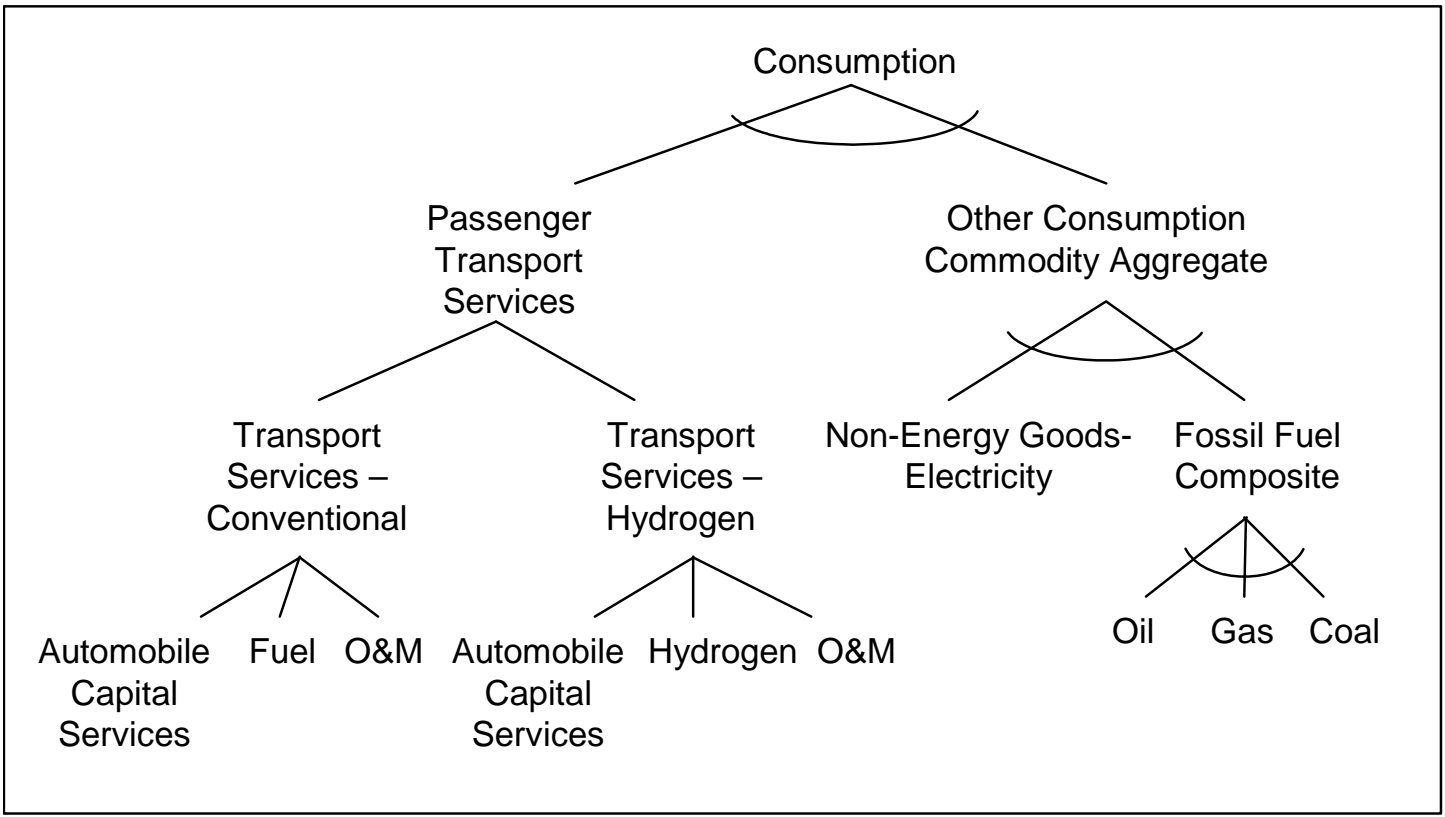

Note: The curvation indicates combinations a constant-elasticity-of-substitution (CES).

Figure 2: Nesting Structure in Household Consumption 

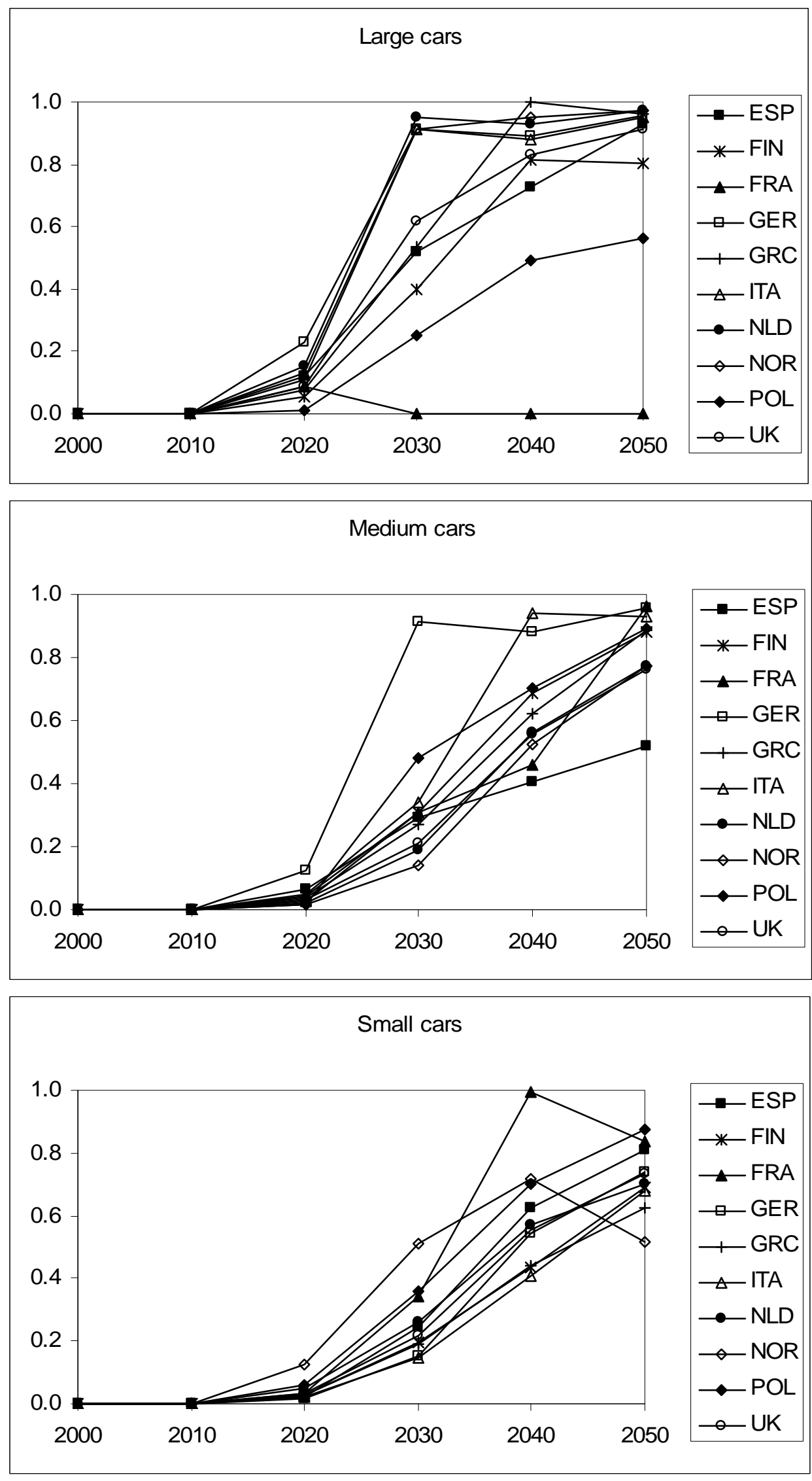

Figure 3: Hydrogen penetration rates for new cars in the $\mathrm{H} 2 \mathrm{H}$ scenario 

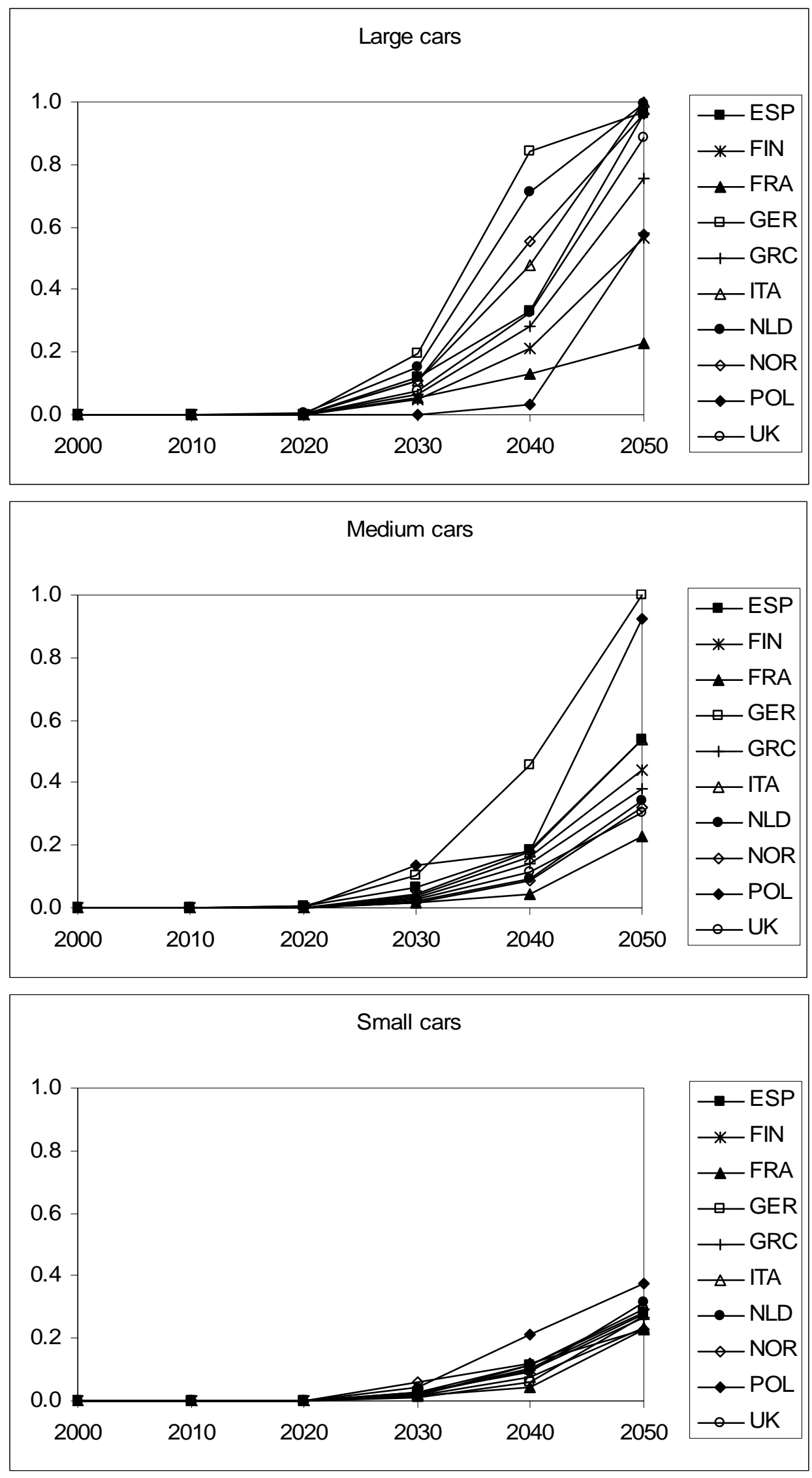

Figure 4: Hydrogen penetration rates for new cars in the L2L scenario 

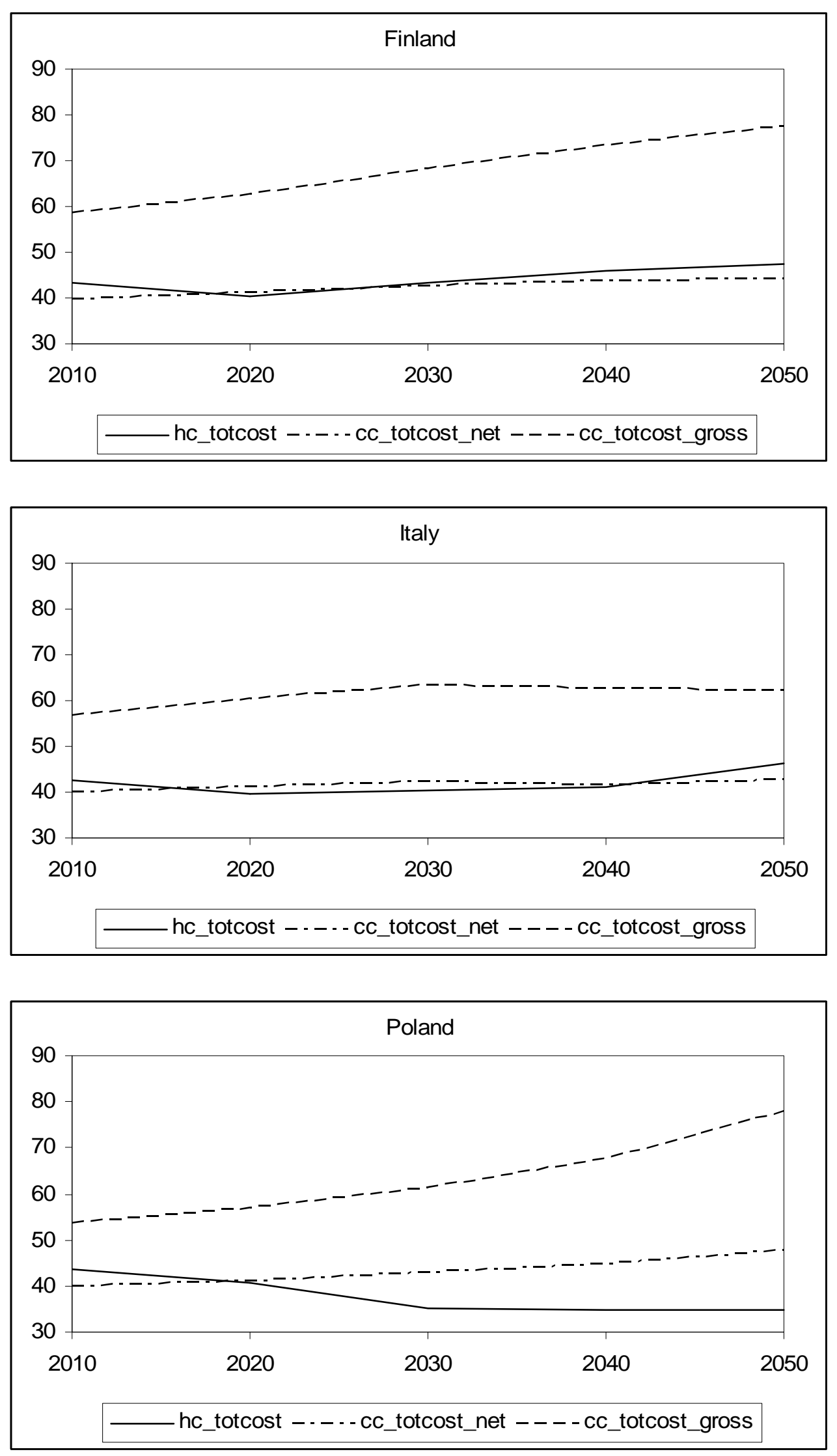

Figure 5: Cost development for large cars in the H2H scenario (in 1,000€) 

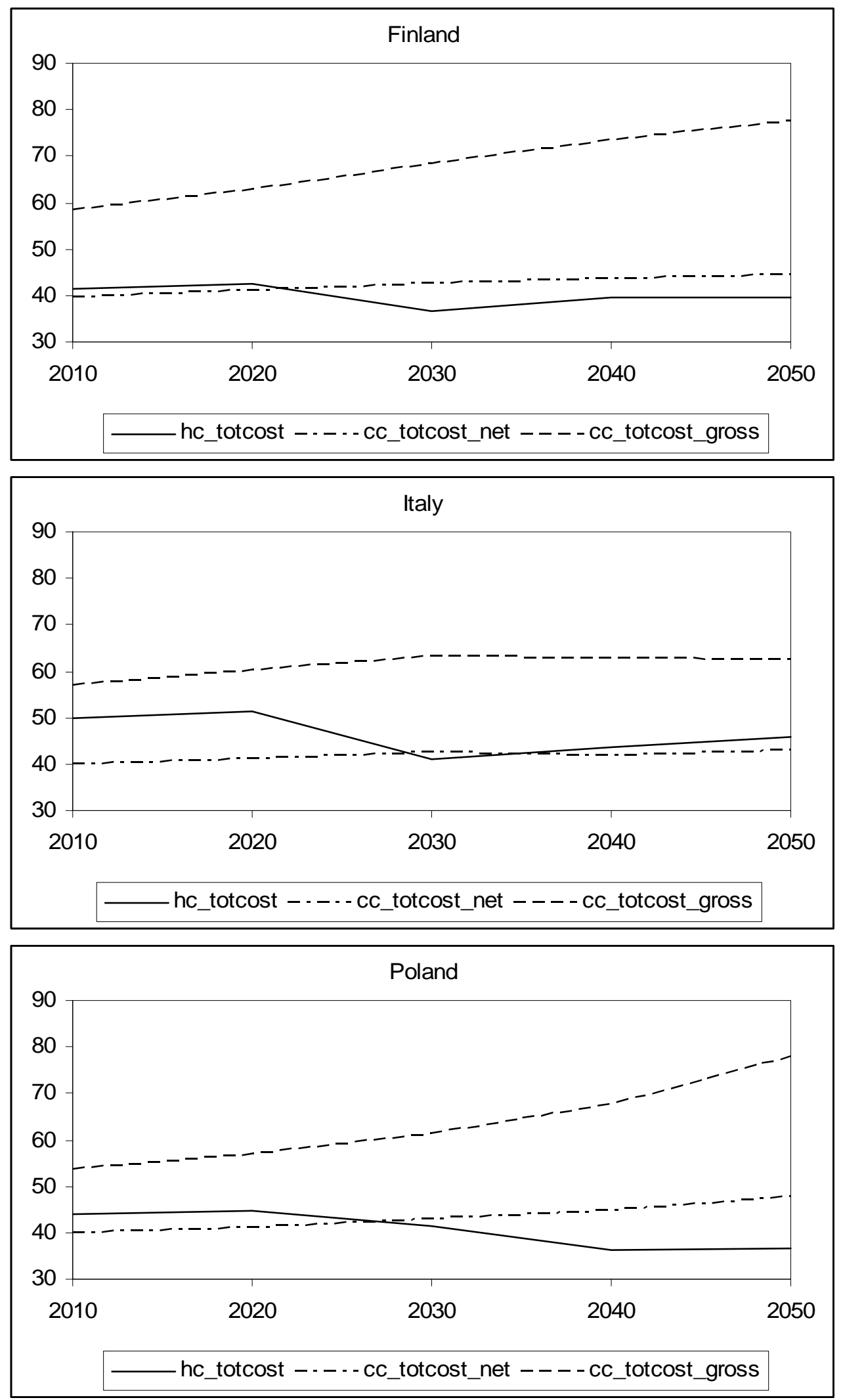

Figure 6: Cost development for large cars in the L2L scenario (in 1,000€) 


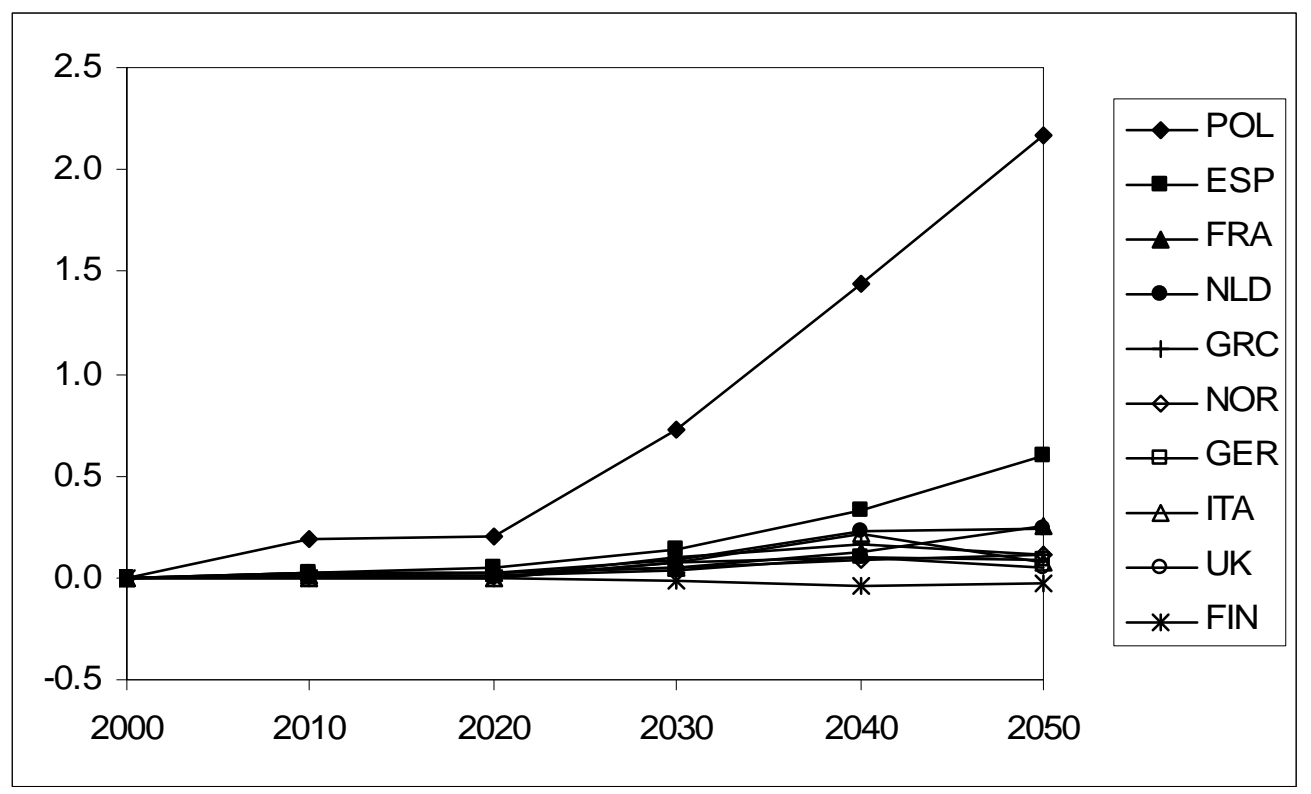

Figure 7: Development of GDP in the $\mathrm{H} 2 \mathrm{H}$ scenario (percentage change relative to baseline)

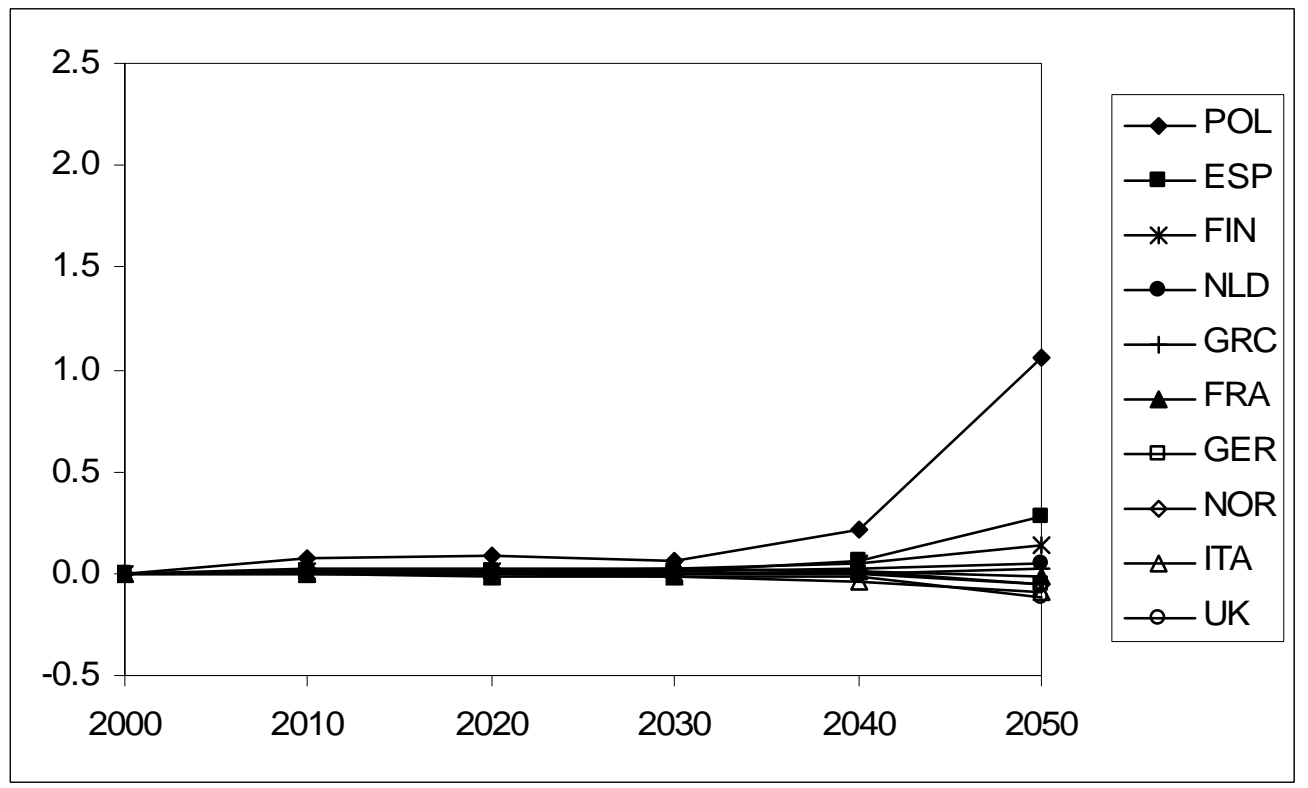

Figure 8: Development of GDP in the L2L scenario (percentage change relative to baseline) 


\begin{tabular}{l|ccc|crc} 
& $\begin{array}{c}\text { Transport } \\
\text { demand }\end{array}$ & $\begin{array}{c}\text { H2H } \\
\text { Real } \\
\text { consumption }\end{array}$ & $\begin{array}{c}\text { Real wage } \\
\text { rate }\end{array}$ & $\begin{array}{c}\text { Transport } \\
\text { demand }\end{array}$ & $\begin{array}{c}\text { L2L } \\
\text { Real } \\
\text { consumption }\end{array}$ & $\begin{array}{c}\text { Real wage } \\
\text { rate }\end{array}$ \\
\hline Finland & 0.10 & 0.04 & -0.01 & 0.11 & 0.09 & -0.03 \\
France & 0.21 & 0.15 & 0.08 & 0.01 & -0.02 & 0.01 \\
Germany & 0.23 & 0.17 & -0.34 & -0.01 & -0.03 & -0.10 \\
Greece & 0.16 & 0.11 & 0.04 & 0.02 & -0.02 & 0.04 \\
Italy & 0.13 & 0.13 & -0.10 & -0.05 & -0.05 & -0.07 \\
Netherlands & 0.37 & 0.33 & -0.02 & 0.15 & 0.12 & -0.03 \\
Norway & 0.38 & 0.31 & 0.11 & 0.23 & 0.18 & 0.10 \\
Spain & 0.47 & 0.42 & 0.03 & 0.17 & 0.15 & 0.01 \\
Poland & 1.35 & 1.24 & -0.44 & 0.52 & 0.46 & -0.32 \\
United Kingdom & 0.14 & 0.15 & -0.31 & -0.03 & -0.02 & -0.17 \\
\hline
\end{tabular}

Table 1: Macroeconomic indicators in 2050 (percentage change relative to baseline)

\begin{tabular}{lcr} 
& $\mathrm{H} 2 \mathrm{H}$ & $\mathrm{L} 2 \mathrm{~L}$ \\
\hline Finland & 0.03 & 0.08 \\
France & 0.13 & 0.00 \\
Germany & 0.13 & 0.00 \\
Greece & 0.09 & 0.01 \\
Italy & 0.06 & -0.07 \\
Netherlands & 0.29 & 0.13 \\
Norway & 0.31 & 0.23 \\
Spain & 0.38 & 0.15 \\
Poland & 1.19 & 0.46 \\
United Kingdom & 0.04 & -0.07 \\
\hline
\end{tabular}

Table 2: Social welfare changes (in percent) 